\title{
The judicious use of theory in social science research
}

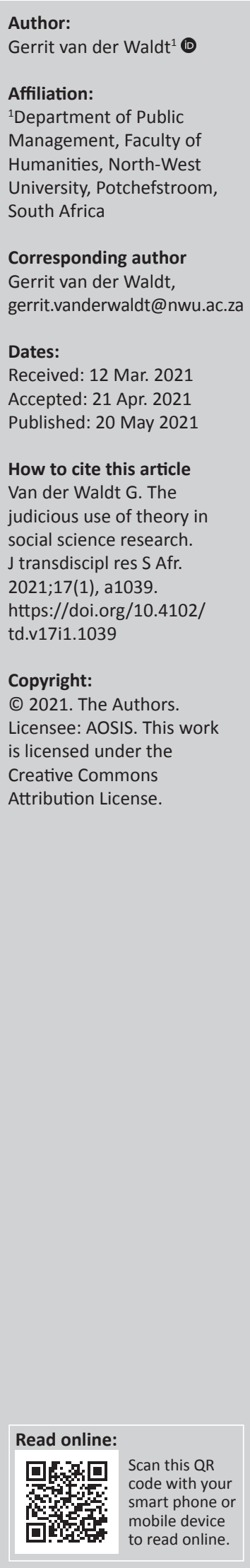

Social science research is focussed mainly on societal concerns and human dynamics. In scholarly domains such as Public Administration, theory is commonly regarded as the backbone of studies, but the why, where and how dimensions of theory in the research process are generally ill-defined. The purpose of this article is to reflect on the use of theory as valueadding catalyst in the research process. Following a literature review based on an interpretivist paradigm, this article aims to enlighten the systematic application of theory in the research process. It is evident that theory's application is based on its unique nature and the aims, nature and type of research. Theory can either inform or structure the research process. This function of theory has significant implications for the research design, methodology, as well as methods and data collection. Understanding the role and significance of theory can definitely enhance the scientific rigour of research and the ability of social science researchers, especially postgraduate students. Such insight may help to ensure that these researchers are capacitated to utilise theory adequately and apply it suitably within the research process. The construction of new knowledge through theory building is critical for social science disciplines to reach maturity.

Keywords: theory; social sciences; research designs; research value chain; theoretical frameworks; research approach; theoretical sampling; triangulation.

\section{Introduction}

In social science research, such as those conducted in fields such as Public Administration and Political Sciences, there appears to be a bifurcation of views on the use of theory. On the one pole are scholars who argue that some form of theoretical abstraction is essential to undertake research. On the other pole, there are those who point out that the nature and type of research will determine the extent to which theory is applied or not. The use of the term 'theory' in popular parlance has added to the confusion of just why, how and where in the research process theory should be applied. Furthermore, based on studies by scholars such as Houston and Delevan, ${ }^{1}$ Bennett et al., ${ }^{2}$ Stout $^{3}$ and Onder and Brower, ${ }^{4}$ it is evident that scholars in social science in general and postgraduate students in particular are typically ill-prepared for theoretically imbedded research. Researchers and students alike generally find it difficult to approach phenomena under investigation from a particular theoretical vantage point. Seemingly they usually underestimate the significance of particular ontological and epistemological dimensions and the theoretical underpinnings in their research designs. Such deficiency is complicated further by study leaders who insist that candidates include meta-theoretical and/or theoretical frameworks or simply 'theory' in their research designs to increase its level of sophistication. The result is that, at times, theory is merely added artificially in research without synthesis or attempts to align the particular theory, the research design and analysis of the findings. Theory and research are thus not always linked inextricably and the theoretical section simply becomes a bolted-on part that is not integrated with the empirical component. ${ }^{5}$

Bryman, ${ }^{6}$ Flick $^{7}$ and Hofstee ${ }^{8}$ confirmed that social scientists are often prone to dismiss research that has no explicit link to theory. Both postmodern interpretivists and logic-positivists, however, generally concur that theory plays a key role in scientific inquiry involving social phenomena. Theory grounds social science endeavours by outlining the meta-underpinnings that constitute social reality (ontology); what is accepted as valid evidence of that reality (epistemology); the means by which the context is investigated (methodology) and the manner in which evidence is gathered (methods).

The purpose of this article is to explore why, where and how theories are useful and, in certain instances indispensable, in social science research. A value-chain model is utilised that illustrates the extent to which theory becomes applicable (i.e. add value) in the research process, comprising problem demarcation, literature reviews, research designs, data analysis and the construction of new (grounded) theory. 


\section{Theory in social science research: The scholarly discourse}

According to Blaikie ${ }^{9}$ and Kelly, ${ }^{10}$ the link between theory and research became a topic of considerable scholarly interest, especially during the 1960s. It became evident that the discourse was guided by at least three broad perspectives. On the one extreme side, some scholars are critical of researchers who remain descriptive in their studies and thus fail to focus their analyses on more abstract concepts or generate new theory. Yiannakis ${ }^{11}$ aptly described this perspective as follows:

Research that is not theoretically informed, not grounded in the existing body of knowledge, or of the 'shotgun' variety that fails to raise and investigate conceptually grounded questions, is likely to generate findings of a narrow and ungeneralisable value.

In this regard, Bryman ${ }^{6}$ argued that without an explicitly stated theory to guide social science research, the study can be merely regarded as 'naïve empiricism'. In even stronger terms, Richards and Richards ${ }^{12}$ pointed out that the main task of qualitative research is 'always theory construction'; Jacard and Jacoby ${ }^{13}$ view theory as 'central in social sciences ... and its construction is at the heart of the scientific process' and Hofstee $^{8}$ argued that 'there are very few higher callings in the academic world than the development of new theories ... it is what moves forward human understanding'. These scholars thus argue strongly that researchers should formulate theories, test it, accept or reject it, modify it and use these foundations as guides to understand and predict specific research outcomes.

In the centre of the discourse continuum, Alvesson and Kärreman, ${ }^{14}$ Ritchie et al. ${ }^{15}$ and Johnston ${ }^{16}$ contemplated whether researchers must conduct their inquiry under the banner of, and in conformity with, a particular theoretical tradition, school or paradigm. These scholars argue that researchers are often 'bewildered' by the multitude of potential approaches (e.g. constructionists, interpretative phenomenological or a grounded theorist approach). They conclude that although it is advisable to have an understanding of the different epistemologies, paradigms and tradition as a way of understanding the range of options available, researchers should be aware of 'epistemological determinism'. Certain researchers rightly feel more comfortable by committing themselves ideologically to a particular theoretical approach. However, not all social science researchers should be forced into a 'theoretical straitjacket'. A more pragmatic and flexible approach is thus proposed to generate knowledge. In this regard, Seale et al. ${ }^{17}$ and Kumar $^{18}$ proposed that researchers should simply base their choice of approach on the nature of the research and the aim of the inquiry. For example, analysis may stop at detailed conceptualisation of the phenomena under investigation, move on to reveal causal relationship between different data sets or use research data to construct general theories. Ritchie et $a{ }^{15}$ advised that a 'hybrid' design is probably most advisable whereby researchers are encouraged to follow a broad social constructionist approach (i.e. grand theory), thereafter, integrate and align the design with middle-range theory.

On the opposite side of the perspective continuum, scholars simply refer to a literature survey as the 'theory' of the research endeavour. Bryman ${ }^{6}$ and Flick ${ }^{7}$ stated that theory in this sense merely refers to the 'literature on a certain topic in the form of accumulated and contextual knowledge gleaned from books and articles'. In a literature survey, it is apparent that the respective arguments in such a discourse depend mainly on the scientific convictions and traditions of the authors, ranging from logic-positivist to interpretivism. Furthermore, it is evident that any discourse on the use of theory in research should be informed by issues such as the aim and nature of the research - basic or applied.

There is, at least, general consensus on the nature of research. According to Bryman, ${ }^{6}$ social science research denotes:

Academic research on topics relating to questions relevant to the social scientific fields. It draws on the ideas and intellectual traditions of the social sciences for conceptual and theoretical inspiration and the interpretation of research findings.

In the same vein, Kumar ${ }^{18}$ argued that research can be regarded as a 'journey embarked on that leads to the discovery of new knowledge or revision of facts, theories, and applications'. The fundamental characteristics of research are that it should, as far as possible have the following attributes: 'be controlled, rigourous, valid and verifiable, empirical, critical, reliable, systematic, arguable, and challengeable'. Scholars generally also concur that research should make a novel contribution to the existing corpus of knowledge of a particular study domain.

The discourse on the use of theory in scientific research makes it clear that characterising the link between theory and research is by no means simple. Constructing a typology in this regard is hampered by several variables. A first variable for consideration is the precise meaning of 'theory'. A second variable is whether research is intended to collect data to test existing or construct new theory. A third potential variable concerns the nature of the research approach and design. Each of these variables is explored briefly in the following sections.

\section{Meaning of 'theory'}

'We don't see things as they are; we see them as we are.' (Anaïs Nin 1961)

The term 'theory' can be used in various ways. In postgraduate research theory is frequently simply used to imply the contextual literature in an area of investigation. The literature thus functions as a proxy for theory. Theory is latent in the literature and according to Abend, ${ }^{19}$ its most common meaning is an explanation of observed regularities. Grix ${ }^{20}$ considered theory as an 'explanatory device' with different 
levels of abstraction to provide 'interpretations of relationships between variables'. Thus, theory represents 'an intellectual description of a phenomenon in its abstract form ...' and serves as a 'heuristic tool for analysis'. Useful theories are generalisable and applicable to different contexts. Smit ${ }^{21}$ defined theory as 'a set of principles that is used to explain a certain phenomenon or phenomena ... [and] is roughly synonymous with ideas or opinions'. De Vos et al., ${ }^{22}$ Jaccard and Jacoby ${ }^{13}$ and Swanson ${ }^{23}$ regarded a theory as a set of statements about the relationship(s) between two or more concepts or constructs. In this regard, theories are related closely to models and hypotheses. Welman and Kruger $^{24}$ regarded a theory as 'a group of logical, related statements, which is presented as an explanation of a phenomenon' or as Hofstee ${ }^{8}$ explained: 'theory brings out order out of chaos and gives meaning to observations'.

Theoretical studies may apply various methods and data to achieve their aims, ranging from mathematical modelling to philosophical argumentation. The given definitions suggest, firstly, that theory consists of concepts, definitions, assumptions and generalisations. Secondly, theory aims to describe and explain phenomena. Thirdly, theory is heuristic because it stimulates and guides the further development of knowledge.

Furthermore, theories show different levels of abstraction. The highest level generally refers to grand theory or metatheory (philosophical concerns, i.e., ontological and epistemological dimensions). ${ }^{25}$ Typically, grand theories include critical theory, symbolic interactionism, structuration theory and structural functionalism. ${ }^{13}$ These grand theories represent the ontological and epistemological assumptions that underpin social science theory. The use of this type of theory is typically complicated by certain research paradigms, traditions and approaches such as positivism, humanism, behaviourism, interpretivism, feminism and constructivism. Grand theories are highly abstract and typically include paradigms such as materialism, critical theory, structuralism, functionalism and symbolic interactionism.

Middle-range theories are domain-specific and tend to link a particular theory with a field of empirical research. ${ }^{26}$ These designs include social conflict theory and contact theory whilst micro-theories are usually aimed at informing specific phenomena such as leadership, motivation and performance. In highly abstract theorising, the formal organisation and arrangement of concepts take precedence over understanding the social reality. According to Rehfeld and Terstriep, ${ }^{27}$ middle-range theories (i.e. mid-range of abstraction) can be regarded as the 'link between the macro and micro levels of observation'. For Blaikie ${ }^{9}$ and Bryman, ${ }^{6}$ middle-range theories, also known as substantive theories, are probably the most commonly used in research and are limited to a specific domain such as public policy or human relations. They further argue that 'middle-range theories' involve a degree of abstraction but are 'close enough for observed data to be incorporated in propositions that permit empirical testing'.
In this regard, middle-range theories thus deal with delimited aspects of social phenomena and cuts across micro (specific) and macro (broad) social issues. Such theories are derived from classical theoretical formulations (i.e. grand and metatheory) and are more focussed on accounts given of specific phenomena such as organisation theory, administrative theory, theory of human motivation and leadership theory. De Vos et al..$^{22}$ also referred to 'low-level' or 'ad hoc theories' constructed to explicate a given set of data.

In addition, Rubin ${ }^{28}$ distinguished implicit from explicit theories. Implicit theories refer to the $a$ priori knowledge and presuppositions of researchers when they do not embrace formal explicit theory. Instead, researchers guide their work either through ideologically held underlying beliefs or pragmatic theories, without actually stating their approach in so many words. Explicit theory is regarded as a formal, scientifically oriented, recognised theory, which the researcher explicitly declares to guide the research more systematically. Rubin ${ }^{28}$ pointed out that implicit theory has to be converted into formal, explicit theory for scientific testing, especially in applied social sciences that address practical concerns. The applied research thus uses theory as instrument to generate potential solutions to concrete problems.

Theories can also be deductive and inductive in nature..$^{20}$ Deductive theories arrive at inferences by employing logical reasoning to a given set of propositions. Inductive theories, on the other hand, arrive at conclusions by observing known facts and feed these into an overarching theory. The deductive approach is a research process that generally commences with a particular theory, which is revised once the research data confirmed or rejected it. ${ }^{6}$ In simple terms, Ritchie et al. ${ }^{15}$ explained that although theory will inform the initial research design, the relationship between design, data and theory is dynamic. Social research can test existing theories or new theories can emerge from the data.

\section{Research aim and type of research}

De Vos et al. ${ }^{22}$ and $\mathrm{Kumar}^{18}$ reasoned that the aim and type of research determine the level of the use of theory. Descriptive, correlational, explanatory and exploratory research all require different degrees of theoretical and conceptual abstraction. Furthermore, two key types of research in the social sciences are known as basic and applied research. Basic research usually aims to serve science in general by enlarging the scientific corpus of knowledge. ${ }^{13}$ This form of research is designed to address philosophical and theoretical problems surrounding phenomena associated with human behaviour and activities. In contrast, applied research is aimed at uncovering (potential) answers to practical concerns. ${ }^{29}$ Emphasis is thus placed on the practical value and application of the generated knowledge. Such application entails the practical implementation of research findings. ${ }^{21}$ Furthermore, a discipline of applied social science can be described as 'utilisation' research. ${ }^{7}$ In applied sciences, disciplines focus strongly on the application of knowledge, being concerned with the usefulness or relevance of the generated knowledge. ${ }^{30}$ 
Basic research deals generally with more abstract constructs, broader themes and aims to contribute to and extend the corpus of knowledge on a phenomenon under investigation, thereby requiring a more in-depth theoretical orientation..$^{29}$ Furthermore, Jaccard and Jacoby ${ }^{13}$ reflected on the role of theory in grounded research designs and instances where emergent theory becomes the main outcome of the research process. Theory emerges or evolves from data, instead of the researcher using data to test theory in more applied, deductive research designs. ${ }^{13}$

\section{Nature of the research approach and design}

Quantitative, qualitative and mixed-method designs represent different research strategies, each describing different roles for theory in its application. Qualitative research can be used to test theories, or at least shed light on them, but such a research strategy is not solely concerned with the generation of theory. 'Pre-specified theories can be tested with qualitative data, but the generation of theory tends to be the preferred approach'.6 Deductive logic in research designs is generally used to test theory and is applied to answer certain research questions based on theoretical considerations. ${ }^{6}$ An alternative is to regard theory as a conglomeration that emerges inductively after collecting and analysing the data associated with the research project. Such theories should be verified iteratively through empirical investigation. In such verification exercise, theory, research and practice usually converge.

Based on the above-mentioned orientation, it is evident that the use of theory in social science research can be placed on a continuum, ${ }^{31}$ ranging as follows:

- research informed by theory

- research in which theory is applied through the design and applications of theoretical frameworks

- research aimed at testing existing theory whereby theoretical constructs are measured and empirically verified

- research aimed at building theory, either new, revised or expanded theory.

\section{The use of theory in the social research value chain}

Theories are generally used to synthesise or combine large amounts of information to discover why an occurrence took place. As stated here, theory development and research methodology cannot be isolated, because it is necessary for relevant methodology to verify and assess theories. New knowledge production by developing theory can be the result of three different processes in research. In this regard it is useful to assess the interrelationship between theory and research as a value chain of scientific engagement. This value chain refers to the initial application of theory at the planning and design phase of the research (i.e. input), the use of theory during the research process to direct data collection and guide data analysis and findings (i.e. processing) and the development of theory during the completion stages of the research (i.e. outcome). These three processes are highlighted briefly here:

- Theory as input: In the first type of design, theory functions as basis for argumentation and the development of a conceptual framework to underpin the research process.

- Theory as process: In this type of arrangement, theory is utilised as evaluation instrument during the research process. A particular theoretical framework (e.g. Marxist theory or neoliberal) is thus used to compare and contrast existing phenomena.

- Theory as output: In this type of research design theory is built as a result of research findings, thus it is also called grounded theory.

The respective processes in the mentioned value-chain are illustrated (Figure 1). This simple linear value-chain model provides a chart to plot the value-adding use of theory in processes of social science research. It should be noticed, however, that research does not necessarily follow a linear trajectory. Ritchie et al., ${ }^{15}$ for example, explained that research often involves an 'oscillation between testing emergent theories and collecting data'. There is thus often an interactive, iterative and non-linear linkage between theory and data, which makes a linear research process unsuitable.

\section{Use of theory as research input}

Bryman $^{6}$ pointed out that the relationship between theory and research holds certain consequences for research. Theory becomes applicable at the beginning of a research project and serves as 'backcloth' and justification for the research that is being conducted. At the outset, the researcher engages in certain theoretical reflections from which a research problem and/or hypothesis is formulated. Bryman ${ }^{6}$ argued further that theory is used to understand the social world and influences what is researched and how research findings are interpreted'. In other words, the issues that are explored are impacted significantly by the availability of appropriate theories. In this way, social research is 'informed and influenced' by theory. On the other hand, such research also 'contributes to theory because the findings of a study

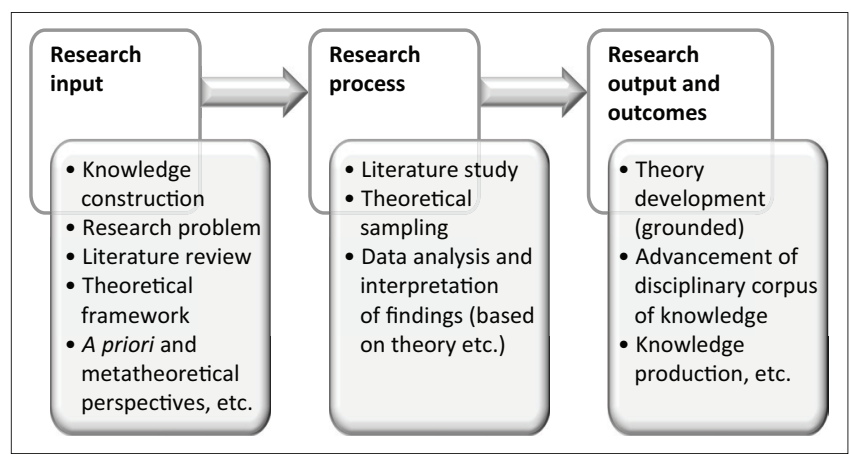

FIGURE 1: Locating theory in the research value chain. 
will feed into the stock of knowledge to which the theory relates'. In this regard, Kelly ${ }^{10}$ explained that theory guides a research design and methodology in at least the following four ways:

- it provides a contextual orientation for the study by focussing attention on the specific aspects under investigation

- it functions as instrument to conceptualise and classify concepts and constructs

- it summarises what is known already about the object of study, including empirical generalisations and systems of relationships between propositions; in addition, pinpoints gaps in the existing knowledge

- it predicts results or findings flowing from the research.

\section{Use of theory in identifying and formulating research problems}

Maree $^{32}$ stressed that a research problem should have a theoretical significance. Such significance refers to the discovery of new conceptual understanding or insight into a research problem. The researcher may, for example, identify an anomaly in the formulation of an existing theory or potential contradiction in its application value within a particular context. Mouton ${ }^{25}$ referred to 'theory-building' studies that may utilise empirical, numerical, textual or hybrid data to construct theory. It is expected that such a theory should provide 'causal accounts of the world, allow one to make predictive claims under certain conditions, bring conceptual coherence to a domain of science and simple understanding of the world'.

Huysamen $^{33}$ and Welman and Kruger ${ }^{24}$ confirmed that a theory may constitute the research problem. Contradictory theories may raise several research questions that could be investigated. In such a case, the purpose of conducting research will be to modify theory, or at least, adjust it to suit particular circumstances. Mouton ${ }^{25}$ explained how theoretical questions should be derived from the research problem. Such questions should typically entail questions related to the most plausible theories, the most convincing explanations, as well as competing theories informing the research problem.

\section{Use of theory in research designs}

Houston and Delevan ${ }^{1}$ argued that to 'produce a meaningful and cumulative body of knowledge' in social science disciplines, research methodology should permit scholars to test and develop theories further. According to George and Bennett $^{34}$ and Creswell, ${ }^{35}$ research in the social sciences has entered a 'new phase' of development conducive to 'cross-method' collaboration and 'multi-method' designs. Predominantly qualitative designs have generally made way for more mixed designs.

The typical where applications of theory in four different types of research designs, namely mixed-method, quantitative, qualitative (deductive) and qualitative (inductive) are illustrated (Figure 2 to Figure 5). A research design can be regarded as a plan or blueprint indicating how to conduct the research..$^{25}$ The application of theory and a particular design that is followed naturally depends on the scope, nature, purpose, hypothesis or central theoretical statements of a particular study. The various depictions are thus generalisations that merely help to illustrate the way theory could be incorporated into these designs.

In this design, typical of applied social sciences, a theory serves as thesis of the study. In other words, theory, comprising

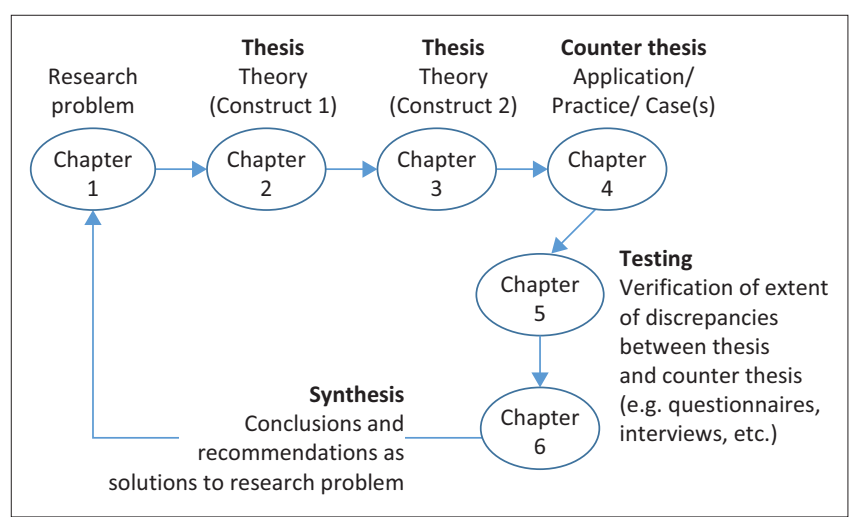

FIGURE 2: Theory in mixed-method applied social science research designs.

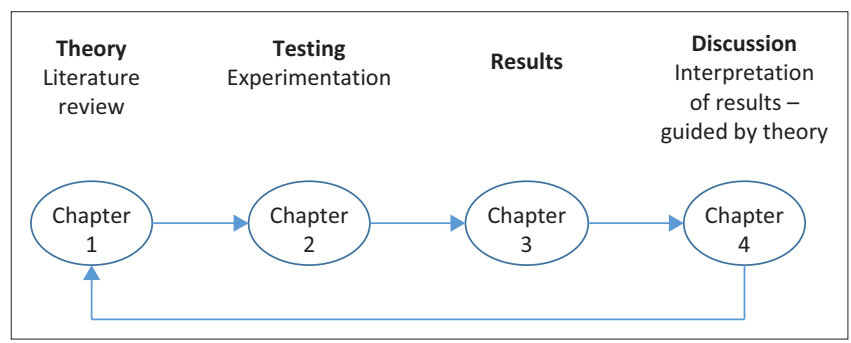

FIGURE 3: Theory in quantitative research designs.

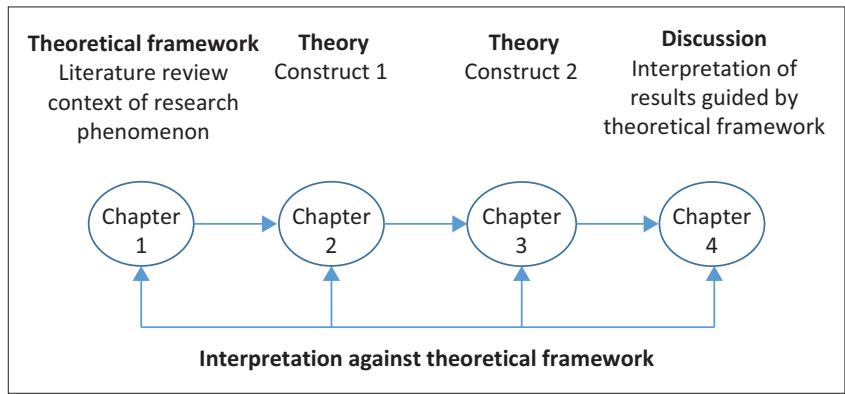

FIGURE 4: Theory in qualitative research designs (deductive).

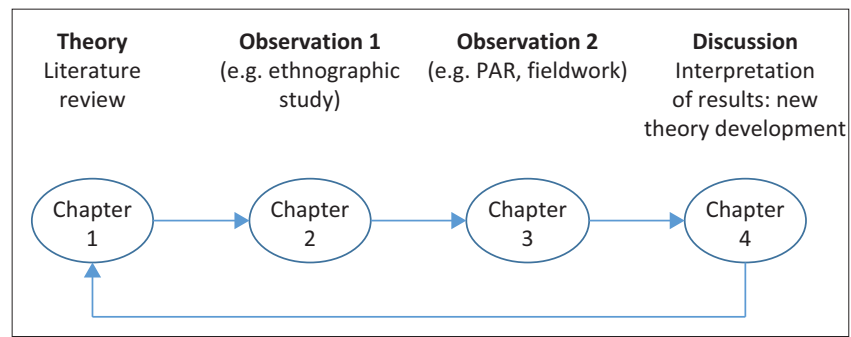

FIGURE 5: Theory in qualitative research designs (inductive). 
the main constructs of the study, provides the researcher with answers to the 'what should be?' question. These theoretical parameters are gauged against the counter thesis, namely the observation of the construct in the context of a practical situation (e.g. a case study). Such situation could imply a particular institution, groups or an observed phenomenon. The counter thesis of the study reflects answers to the 'what is?' question. Testing or verification of the extent or level of discrepancies between the 'what is' (case) and the 'what should be' (theory) then follows. The testing may take the form of questionnaires or interviews with a purposive sample of respondents or participants in the case. The research process builds up to the synthesis in which the researcher makes recommendations to bridge or overcome the discrepancies between the thesis and counter thesis as solution(s) for the problem identified in Chapter 1 of the study.

In a typical quantitative research design, the researcher commences with a theoretical framework (Chapter 1) based on a hypothesis against which empirical testing is performed (Chapter 2). The interpretation of results is again guided by the mentioned theoretical framework (Chapters 3 and 4). This design is commonly applied in natural sciences.

In a deductive qualitative research design, theory generally underpins the entire study. Chapter 1 typically aims to establish a comprehensive theoretical framework derived from a robust literature review. The respective constructs of the study and the interpretation of results flowing linearly from the theoretical investigations are based on the theoretical framework. This framework thus provides the parameters, assumptions and premises on which interpretations and conclusions are made.

Social science disciplines such as Anthropology and Sociology often utilise an inductive qualitative research design. These studies are highly interpretivist and typically utilise ethnography and participatory action research (PAR). Ethnographic studies systematically analyse people and their cultures including their customs, habits and mutual differences. Such studies are generally intended to investigate cultural phenomena where the researcher observes certain behaviour and conduct in society. In the chosen design, (new or grounded) theory is derived inductively from observations through techniques such as discourse analysis, document analysis, content analysis, as well as videos and audio transcription. A particular theoretical orientation also guides the research setting, the design and implementation of the research. The orientation focusses on instrumentation of data collection such as participant observation, field notes, interviewing and gathering of artefacts, as well as the analysing of data, selecting the target population and sampling.

\section{Use of theory in literature reviews}

Hofstee $^{8}$ explained that theory can be considered as the 'knowledge and theoretical base' of research. The primary aim of the literature review is generally to consider the work of previous scholars, determining the existing theory base for the research and ascertaining how the particular study aligns with prior studies in this field. In this regard, Kumar ${ }^{18}$ claimed that the literature review enhances and consolidates the theoretical base of the area of scientific inquiry and guides the interpretation of research results and findings. Neuman ${ }^{36}$ added that a robust literature review should 'locate the research problem in a body of theory'. Such a review should also indicate the path of prior research and pinpoint the area of knowledge the study is intended to expand.

Flick $^{7}$ pointed to consensus in the academic fraternity that researchers should be 'familiar with the [theoretical] ground on which they move and wish to make progress; finding new insights needs to be based on knowing what is known already'. Flick adds that theoretical, methodological and empirical literature should be reviewed in this regard to contextualise the problem and eventually, compare and generalise research findings. Theoretical literature should help the researcher to determine what facts are known already, what theoretical debates or controversies exist, what questions remain open and which theories are applicable. Theory typically reveals the types of variables that must be considered and thereby directs the instruments of data collection. ${ }^{9}$ Bless and Higson-Smith ${ }^{37}$ pointed out that a literature review should allow the researcher to become acquainted with different theories, in order to shape the design of a theoretical framework.

Frodeman ${ }^{38}$ and CohenMiller and Pate ${ }^{39}$ also reflected on the trend in social sciences according to which research problems are informed by theories that are developed in other disciplines. The scholars thus stress that a literature review should provide for interdisciplinary perspectives to widen the theoretical bases.

\section{Use of theory to construct theoretical frameworks}

According to Maree, ${ }^{32}$ a theoretical framework provides an overview of perspectives and functions as platform to plan the study on the basis of existing theory. Kumar ${ }^{18}$ concurred and added that theoretical frameworks serve as 'guides or parameters' for a literature review. From his side, Flick ${ }^{7}$ viewed a theoretical framework as a map or model of alternative theories available against which the results of the study can be interpreted. Maree ${ }^{32}$ added that a theoretical framework should function as 'justification instrument' to substantiate why a particular theory is used and how it has been constructed and framed to inform the particular study.

Theoretical frameworks emerge from literature reviews once researchers have established the theoretical underpinnings of the research problem. In this regard, $\mathrm{Kumar}^{18}$ referred to a paradox in research because a theoretical framework cannot be developed unless a thorough literature review has been conducted; however, without such a framework a literature review is unguided and thus ineffective. It should be observed that a literature review is usually universal and 
very general at the initial stages of the research process. However, as a theoretical framework begins to emerge, the review will become far more focussed and specific.

A decision to use a particular theory has a number of methodological consequences. Such a decision will, for example, set the frame for operationalising the relevant features of the issue under investigation, the extent to which the theory is compatible with the research questions and direct the analysis and interpretation of the findings. Similarly, Bless and Higson-Smith ${ }^{37}$ stated that theory may provide an orientation for the study in general and the gathering of data in particular. Depending on the nature and purpose of the study, the choice of theory can either inform or control the research method. Maslow's hierarchy of human needs theory, may, for example, inform a theoretical orientation of human motivation, or, each of the five human needs identified in the theory should be tested empirically, thus controlling the method.

The placing and application of specific theories within a field of study are illustrated (Figure 6). In this example, public policy can be regarded as a study domain within Public Administration. Mass-elite theory is one of the theoretical models according to which public policy can be studied. The application in this example is policymaking in government.

\section{Use of theory in conceptualisation}

Scholars such as De Vos et al. ${ }^{22}$ and Jacard and Jacoby ${ }^{13}$ concurred that strong operational definitions are required for all constructs and concepts employed in research. Bless and Higson-Smith ${ }^{37}$ maintained that conceptual clarity (based on theory) is essential to develop comprehensive, nonambiguous, operational definitions of key concepts and constructs associated with the study. In this regard, a conceptual framework should guide the research design and data-collection instrumentation. Mouton ${ }^{25}$ maintained that concepts are the 'building blocks' for all sense-making endeavours. Therefore, concepts can also be considered the building blocks of theory, which conveys a particular relationship between concepts. Jacard and Jacoby ${ }^{13}$ referred to this relationship as a rudimentary 'conceptual system' that provides a 'mental map' for research. These conceptual systems thus serve as theoretical guides to identify, organise, explain or predict certain outcomes.

Van der Waldt ${ }^{40}$ posited that elementary concepts such as 'table', 'contract' or 'window' generally do not require any theoretical orientation whilst the conceptualisation of

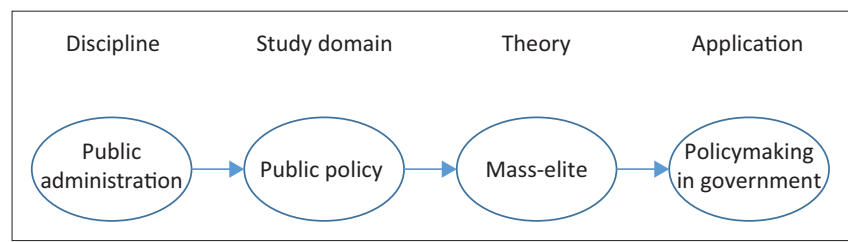

FIGURE 6: Theory application in research. abstract constructs such as 'democracy', 'leadership', 'productivity' and 'attitude' demands a more thorough and detailed orientation. In the case of 'democracy', for example, theories should be explored that are related to direct, representative, non-partisan, dominant party, totalitarian, parliamentary and constitutional democracies.

\section{Use of theory in the research process}

Grix $^{20}$ highlighted the need for theoretical 'devices' that function as explanatory instruments in the research process. These devices range in complexity and abstraction. Such a range includes theoretical frameworks, models, ideal type, typologies and concepts. These devices are typically designed during the research 'input' link in the value chain, after which they are used as meaning-making tools to explain complex social phenomena during the research process.

Grix ${ }^{20}$ suggested that theories 'select out certain factors as the most important or relevant if one is interested in providing an explanation of an event ... theories are of value because they structure all observations'. In this regard, theories can be used as classification systems to help determine which data and facts to collect. ${ }^{6}$

\section{Data analysis and interpretation of research findings}

Research findings and the interpretation of results have limited relevance if it is presented outside a particular theoretical framework. Bless and Higson-Smith ${ }^{37}$ explained the fundamental relationship between empirical data and theory as the 'explanatory framework'. Theory allows a researcher to confirm, disprove, improve or formulate a theory. In addition, theory allows for a classification and conceptualisation of research findings.

Jaccard and Jacoby ${ }^{13}$ pointed out that the discussion section in research projects should reflect whether the empirical tests were consistent with the theory. In the same vein, De Vos et al. ${ }^{22}$ proposed that the findings must be verified against the larger stated grand and middle-range theories. If it was found that the theory is not supported, revisions are suggested. If the theory was found to be supported, the researcher should highlight the implications of the results and specify the further required research. This would mean applying the theory in different contexts, populations or conditions, thereby establishing the generalisability of the particular theory. Hofstee ${ }^{8}$ cautioned that the researcher must be certain of the findings, what they mean, and how far they can be generalised, before making suggestions to modify or expand a particular theory. The likelihood of speculation should thus be minimised.

Maree $^{32}$ suggested that research findings should be interpreted by situating the results within the broader existing body of knowledge, which includes theory and should indicate any similarities, contradiction, gaps and new insights. Ritchie et al. ${ }^{15}$ in this regard mentioned several ways 
in which researchers can link findings to existing theory. Findings should be 'located' within current theory. Ultimately the researcher, through inferential or explanatory arguments, should reflect on the ways in which data support or contradict theory, resulting in the widening and deepening of thought patterns in both theory and practice. Theory thus drives the gathering and analysing of data. Regarding the application of theory in research, Smit ${ }^{21}$ argued that it 'gives direction' to the research and 'organises facts into a systematic source of knowledge'. Application thus generates new knowledge by focussing thinking on new aspects.

As illustrated, the development of theoretical criteria or yardsticks to gauge or evaluate the results is essential in applied research (Figure 3). Such criteria are necessary to contrast and compare current practice (i.e. the 'what-is' dimensions), with theory (e.g. the 'what- should-be' dimensions). Theory thus provides the researcher with approaches and principles against which to measure observed practical applications, such as systems, structures and behaviour.

\section{Theoretical sampling and triangulation}

According to Jacard and Jacoby, ${ }^{13}$ exponents of grounded theory emphasise the importance of theoretical sampling in the context of constructing theory from data. Theoretical sampling is a type of purposive sampling that is typically applied after initial data have been collected and analysed in a preliminary stage. The purpose is to increase the diversity of theoretical perspectives that may help researchers identify and define the constructs and propositions that are evolving. ${ }^{15}$ The motivation is thus not to obtain full representation, but rather extract new information that provides perspectives on the boundaries and nature of concepts and its interrelationships. Theoretical sampling thus contributes to the construction of theory by adding diverse categories, themes and perspectives. On a similar track, Flick ${ }^{7}$ referred to 'triangulation of theories' as 'approaching data with multiple perspectives and hypotheses in mind ... Various theoretical points of view could be placed side by side to assess their utility and power'. In other words, triangulation contributes to conceptual research by expanding different perspectives to existing knowledge.

\section{Use of theory as research outcome}

Theory can also add significant value during the outcome phase of research. Theory as outcome generally refers to the broadening of theoretical insight whereby theoretical ideas emerge from empirically researched data, usually through thematic analysis and coding of data. ${ }^{23}$ In this regard, the maturity of academic disciplines in the social sciences should be considered. Within these disciplines, theory provides the framework for the construction and production of scholarly knowledge. Over time a corpus body of knowledge emerges that is distinct from that of other disciplines. It is evident that the majority of postgraduate studies simply tend to repeat prior studies without a view to confirm their validity.
Existing theory is thus merely 'recycled'. Such an approach dramatically impoverishes social science disciplines. Therefore, the field of study should be enriched by developing theory (i.e. grounded theory). According to Van der Waldt, ${ }^{41}$ the idea of disciplinary relevance is generally connected to a sense that scholars should produce new knowledge that will capacitate and guide the world of work. In other words, research should be career-specific or work-integrated to an extent.

Furthermore, theory may help the researcher to trace the paradigmatic development of a particular discipline. The scholarly study of a discipline only becomes meaningful if the existing praxis is measured against prevalent paradigms guiding thought patterns about specific issues in a discipline (e.g. classic, neoclassical and contemporary) and to interpret the rationale of current thinking. Theory may also help categorise or cluster ideas and domain-specific concepts. The study of a discipline such as Public Administration, which is highly diverse and multidisciplinary, may rapidly become disorganised without the demarcation of certain subfields of study. Theories linked to disciplines can, for example, be categorised into grand, middle-range, classical and contemporary. Categories may also entail theories of political control, bureaucracy, governance and public institutional theories to inform or interpret social phenomena.

\section{Conclusion}

The purpose of this article was to explore the significance of theory in social science research by reflecting on the ways theorising could add value in the research value chain. In the process, answers were provided to the why, where and how dimensions in the use of theory. It is evident that theory may simply inform social research. However, depending on the aims, nature and type of research, theories are generally indispensable. They contribute by enhancing the value of research and building the maturity of the corpus of knowledge for social science research.

It is probably advisable to pursue a more pragmatic approach in the use of theory in social research. Researchers should attempt to reconcile the competing demands of scientific rigour and the applied relevance of their findings. However, more experienced social scientists should continuously conduct basic research, thus constructing new theory to develop the meta-perspectives and theoretical basis of social science disciplines. Theory should be applied scientifically and rigorously in key aspects of the research process, which consists of conceptualisation, design, data collection, analysis and interpretation. Such judicious use of theory in social research will surely enhance understanding of complex social phenomena and build the scientific validity and credibility of social research findings.

\section{Acknowledgements Competing interests}

The author declares that no competing interest exists. 


\section{Author's contributions}

G.v.d.W. declares that he is the sole author of this research article.

\section{Ethical considerations}

This article followed all ethical standards for a research without direct contact with human or animal subjects.

\section{Funding information}

This research received no specific grant from any funding agency in the public, commercial or not-for-profit sectors.

\section{Data availability}

The author confirms that the data supporting the findings of this study are available within the article.

\section{Disclaimer}

The views and opinions expressed in this article are those of the author and do not necessarily reflect the official policy or position of any affiliated agency of the author.

\section{References}

1. Houston DJ, Delevan SM. Public administration research: An assessment of journal publications. Publ Admin Rev. 1990;50(1):674-681. https://doi. org/10.1177/009539979402600207

2. Bennett $A$, Barth $A$, Rutherford K. Do we preach what we practice? A survey of Methods in Political Science Journals and Curriculam. Polit Sci Polit [serial online]. 2003 [cited 2020 Sept 27];36(3):373-378. Available from: https://www.jstor.org/ stable/i370013

3. Stout M. Preparing public administration scholars for qualitative inquiry: A status report. Publ Admin Res. 2013;2(1):11-30. https://doi.org/10.5539/par. v2n1p11

4. Onder M, Brower RS. Public administration theory, research, and teaching: How does Turkish public administration differ? J Publ Aff Educ. 2017;19(1):117-139. https://doi.org/10.1080/15236803.2013.12001723

5. Houston DJ, Delevan SM. The state of public personnel research. Rev Publ Pers Admin. 1990;11(1-2):97-111. https://doi.org/10.1177/0734371X9001100107

6. Bryman A. Social research methods. Oxford: Oxford University Press; 2016; p. 19, 22, 19, 299 .

7. Flick U. An introduction to qualitative research. 5th ed. London: Sage; 2014; p.8, $14,66,111,218$

8. Hofstee E. Constructing a good dissertation: A practical guide to finishing a Master's, MBA or PhD on schedule. Johannesburg: EPE; 2018; p.30, 130, 159.

9. Blaikie N. Designing social research. Cambridge: Polity Press; 2000; p.145.

10. Kelly $M$. The role of theory in qualitative health research. Fam Pract. 2010;27(3):285-290. https://doi.org/10.1093/fampra/cmp077

11. Yiannakis A. Toward an applied sociology of sport: The next generation. In: Yiannakis A, Greendorfer SL, editors. Applied sociology of sport. Champaign, IL: Human Kinetics; 1992; p. 8.

12. Richards TJ, Richards L. Using computers in qualitative research. In: Denzin NK, Lincoln YS, editors. Handbook of qualitative research. London: Sage; 1994; p. 450.
13. Jacard J, Jacoby J. Theory construction and model-building skills: A practical guide for social scientists. New York, NY: Guilford, 2010; p.3, 28, 48, 269.

14. Alvesson M, Kärreman D. Qualitative research and theory development: Mystery as method. London: Sage; 2011.

15. Ritchie J, Lewis J, Nicholls CM, Ormston R. Qualitative research practice: A guide for social science students and researchers. London: Sage; 2013; p.19, 336.

16. Johnston A. Rigour in research: Theory in the research approach. Eur Bus Rev. 2014;26(3):206-217. https://doi.org/10.1108/EBR-09-2013-0115

17. Seale S, Gobo G, Gubrium JF, Silverman D. Qualitative research practice. London: Sage; 2007 ; p. 7

18. Kumar R. Research methodology: A step-by-step guide for beginners. Los Angeles, CA: Sage; 2014; p. 12, 13, 48, 56

19. Abend G. The meaning of 'theory'. Soc Theor. 2008;26(June):173-199. https:// doi.org/10.1111/j.1467-9558.2008.00324.x

20. Grix J. Demystifying postgraduate research: From MA to PhD. Birmingham: University of Birmingham Press; 2001; p. 40.

21. Smit GJ. Research: Guidelines for planning and documentation. Pretoria: Southern; 1995; p. 3

22. De Vos AS, Strydom H, Fouché CB, Delport CSL. Research at grass roots: For the social sciences and human service professions. 3rd ed. Pretoria: Van Schaik; 2005; p. $28,42,84,106$.

23. Swanson RA. Theory building in applied disciplines. San Francisco, CA: BerrettKoehlers; 2013; p. 5.

24. Welman JC, Kruger SJ. Research methodology for the business and administrative sciences. Cape Town: Oxford University Press; 1999; p. 11

25. Mouton J. How to succeed in your Master's and Doctoral Studies: A South African guide and resource book. 11th ed. Pretoria: Van Schaik; 2011; p. 20, 55, 109.

26. Boudon R. What middle-range theories are. Contemp Soc. 1991;20(4):519-522. https://doi.org/10.2307/2071781

27. Rehfeld D, Terstriep J. Middle-range theorising: Bridging micro- and Meso-level [homepage on the Internet]. SIMPACT Working Paper, Vol 2015, No 1. Gelsenkirchen: Institute for Work and Technology; 2015; p. 3-9 [cited $2021 \mathrm{Feb}$ 15]. Available from: http://www.simpact-project.eu/publications/wp/WP_201501_Rehfeld_Terstriep_MRT.pdf

28. Rubin HJ. Applied social research. London: Charles E Merrill; 1983; p. 53, 59.

29. Higgins ET. Making theory useful: Lessons handed down. Pers Psych Rev. 2004;8:138-145. https://doi.org/10.1207/s15327957pspr0802 7

30. Lynn LE. New frontiers of public administration: The practice of theory and the theory of practice. Polit Sci Polit. 2008;41(1):3-9. https://doi.org/10.1017/ S1049096508080323

31. Van der Waldt G. Theories for research in Public Administration. Afr J Publ Aff [serial online]. 2017 [cited $2021 \mathrm{Feb} 02$ ];9(9):183-202. Available from: https:// dspace.nwu.ac.za/bitstream/handle/10394/28276/2017Theories. pdf?sequence $=1 \&$ isAllowed $=y$

32. Maree JG. Complete your thesis or dissertation successfully: Practical guidelines. Cape Town: Juta; 2012; p. 10.

33. Huysamen GK. Methodology for the social and behavioural sciences. Halfway House: Southern; 1994; p. 2.

34. George AL, Bennett A. Case studies and theory development in the social sciences. Cambridge, MA: MIT Press; 2004; p. 1.

35. Creswell JW. Research design: Qualitative, quantitative, and mixed-method approaches. 3rd ed. London: Sage; 2009; p. 12.

36. Neuman WL. Social research methods: Qualitative and quantitative approaches. 4th ed. Boston, MA: Allyn \& Bacon; 2000; p. 446.

37. Bless C, Higson-Smith C. Fundamentals of social research methods: An African perspective. Cape Town: Juta; 1995; p.10, 22.

38. Frodeman R. The Oxford handbook of interdisciplinarity. New York, NY: Oxford University Press; 2010; p. 67.

39. CohenMiller AS, Pate PE. A model for developing interdisciplinary research theoretical frameworks. Qual Res. 2019;24(2019):1211-1226.

40. Van der Waldt G. Constructing conceptual frameworks in social science research. J Transdiscip Res S Afr. 2020;16(1):1-9. https://doi.org/10.4102/td.v16i1.758

41. Van der Waldt G. Public administration and management as study domain: The relevance debate. Afr J Publ Aff. 2013;6(4):72-85. https://doi.org/10.13140/ RG.2.1.4986.2882 